\title{
Understanding Student Anti-Racism Activism to Foster Social Justice in Schools
}

\author{
Darren E. Lund \\ University of Calgary \\ Maryam Nabavi \\ University of British Columbia \\ Canada
}

The purpose of this study was to understand the experiences of students and teachers who form voluntary coalitions or school projects to address issues of racism and discrimination. The authors draw on several years of experience of facilitating student activism and findings from a recent collaborative research project. This research documents and analyzes experiences from a number of school settings across western Canada but has implications for student social justice activism everywhere. The study examines how students get involved with voluntary coalitions to undertake anti-racism initiatives to enhance the social acceptance of marginalized students and how they can overcome sources of resistance to promote inclusion.

\author{
Subject Location \\ Background/Rationale \\ Theoretical Framework \\ Methodology \\ Participant Selection \\ Interview Findings \\ Reasons for Involvement \\ Social Impact of Involvement \\ Successes and Struggles \\ Conclusion \\ Notes \\ References \\ Appendix
}

For the past several decades there has been a strong academic interest in promoting the ideals of acceptance of diversity and inclusive practices in schools. However, the current research on anti-racism education and multicultural education has included relatively few analyses of the experiences of student activism within school settings. We undertook this study ${ }^{1}$ as a means of analyzing how and why students engage in existing social justice programs and of documenting some of their challenges, in their own words, focusing for practical purposes on the prairie region of western Canada. We sought to understand the experiences of some students and teachers who form voluntary coalitions or who undertake specific school projects to address issues of racism 
and discrimination; this paper focuses on findings from the student participants in the project.

\section{Subject Location}

This project builds on the researchers' combined expertise and experiences in anti-racism research and activism. We accept the complexity of gendered and racialized relations and have conducted this research from differing subject positions. Most helpful for us has been the work of James Banks (1998) on the typology of cross-cultural researchers; we have come to better understand our roles as an "external insider" and an "indigenous insider," respectively, and the particular types of risks and benefits he notes for each role (pp. 7-9). Further, we have both strived to "conduct research that empowers marginalized communities" (p. 15). As a high school teacher, Lund formed an award-winning student activist program, Students and Teachers Opposing Prejudice (STOP) that has remained a model of collaborative anti-racism activism for two decades (Alberta Human Rights Commission, 2000). For the past several years he has sought a clearer understanding of the practical realities of anti-racism work among activist teachers and students (Lund, 1998, 2003, 2006) and has recently explored more specifically how his own privileges as a straight, able-bodied White male have played themselves out in his scholarly and activist work (Lund, 2007). Nabavi is a first-generation immigrant woman of color. She has extensive experience working in the social justice field, has lived and worked overseas, and has been involved nationally in social justice research, policy, and activism. For both of us, the interlocking forms of oppression are embedded in our personal and political work.

\section{Background/Rationale}

As researchers and activists we have an overarching goal to understand and analyze the complex nature of how students and teachers form and sustain coalitions and projects in schools. Although we see our work as emerging from the contested field of multicultural education, we also acknowledge the many problematic aspects that have been associated with this broad tradition. The word "multicultural" rarely evokes a neutral response in this country. Canada remains one of the few nations with multicultural ideals entrenched in national government policy, although it is often seen as being about preserving the status quo, viewing (non-White) immigrants as in need of assistance to assimilate to mainstream norms, taking a superficial view of culture and identity, and ignoring issues of systemic racism and intersections with other oppression. Some Canadian researchers (e.g., Ghosh, 1996; James, 2005; Moodley, 1995) have outlined approaches to multicultural education that pay some attention to issues of power and privilege, but it remains a field that is viewed by many as an inadequate response to racism. Likewise, in the US, many multicultural education 
proponents have moved toward more critical engagement with multiple forms of oppression (Banks, 2002; Sleeter \& Bernal, 2004).

A contemporary collective denial that ignores the abiding existence of racism in Canada is refuted by a long history of discriminatory government policies and practices. Since Europeans began arriving, systematic discrimination has been practiced against individuals and groups based on racist ideologies and ethnocentric views, beginning with the colonization of this continent's indigenous peoples. Official government policies, composed and imposed with popular public support, served to entrench racialized segregation in schools, forced assimilation of Aboriginal Canadians, racialized immigration restrictions, promoted anti-Semitism, enabled the mistreatment of Chinese immigrant railway workers, and orchestrated the displacement and internment of Japanese-Canadians (see Boyko, 1995). For various reasons, such unsavory aspects of Canadian history have been missing or understated in current social studies school materials. Anti-racism education advocates for the close attention to these and more contemporary manifestations of racism in schools and society (e.g., Dei, 1996; Dei \& Calliste, 2000).

In spite of the precarious relationship between multiculturalism and antiracism, within the Canadian context, they cannot be explored independent of one another because the underpinnings of multiculturalism often shape anti-racism discourse in Canada. Directing specific attention to anti-racism education includes a critical and dynamic understanding of racism, refined and revised in light of emerging insights from our collaboration with research participants. Clearly, racism is just part of a larger and intertwined set of social and institutional practices and policies that create and preserve an inequitable playing field. Groups who are most typically affected cannot easily be categorized or described in simplistic terms, and have personal agency of their own, as clearly outlined by a growing number of cultural theorists and researchers (e.g., Giroux, 2003; McCarthy \& Dimitriadis, 2005; Yon, 2000). Our approach emerges from a critical theoretical stance of "integrative anti-racism," described in greater detail in the section that follows. In our educational research we strive for solidarity with political struggles across issues of race, ethnicity, class, gender, sexual orientation and other contested elements of social identity (e.g., Dei \& Calliste, 2000; Sleeter \& Bernal, 2004; Solomon \& Levine-Rasky, 2003). We have followed Hall's (1992) theorizing on culture and identity, a perspective that recognizes race as a social construction while acknowledging the racialized context of schooling and the pervasiveness of racism.

Many teachers and students have chosen to organize initiatives to foster acceptance in schools across North America, but relatively few sources exist for meaningful guidance in forming, sustaining, and studying school-based coalitions. A pilot project for this research sought to answer this need by developing an interactive web-based resource for school activists, entitled the Diversity Toolkit, $\stackrel{?}{\text { based }}$ on interviews with student and teacher activists. The 
researchers made use of this resource as a way to focus this investigation on actual uses and understandings of how students and teachers implement social justice initiatives.

As in other Western democracies, Canadian public schools are microcosms of our pluralistic society and exciting locations for studying how we might best approach living productively with diverse social differences in this country. They can also be sites of conflict based on differences in social identity with their growing diversity mirroring Canada's recent demographic changes (Li, 2003) such as the $13.6 \%$ increase in the foreign-born population from 2001-2006 (Statistics Canada, 2006). Developing proactive educational approaches to the cultural diversity brought about by immigrant and refugee students needs to honor Li's reminder that integration is not simply about confining people to rigid expectations and norms; rather, "integration is about giving newcomers the right of contestation, the legitimacy of dissent, and the entitlement to be different" ( $p$. 330).

An ever-growing body of academic literature in both Canada and the U.S. shows promising efforts to reflect cultural sensitivity in teaching materials, training and practices (Dei \& Calliste, 2000; Marx, 2004; Nieto, 2004; Sleeter, 1996; Solomon \& Rezai-Rashti, 2001). Recent educational research that examines administrative and policy changes necessary to address the growing ethnocultural diversity in schools (Apple, 1999; Corson, 2000; Ghosh \& Abdi, 2004) has offered numerous insights into educational reform, including the need to address non-discriminatory hiring practices, adequate representation of marginalized groups in curricular materials, culturally sensitive educational programming, respectful parent and community engagement, and other specific approaches to attaining equity and social justice for all students. Turning to the lived experience in schools, the researchers have designed this project to examine the views of students engaged in collaborative, school-based approaches to fostering integration as one possible response to the complexities that accompany ethno-cultural and other diversity.

Research consistently reveals that many young people continue to experience racism, even here in the proudly multicultural nation of Canada (Alberta Human Rights Commission, 1993; Creese \& Kambere, 2003; Pruegger \& Kiely, 2002; Statistics Canada, 2002). Engaging student activists in educational research resists a growing conservative backlash toward youth culture. Giroux (1996) notes that "youth" as a social category is too often used as a catalyst for panic and fear. More recently, Giroux (2003) has observed: "If not represented as a symbol of fashion or hailed as a hot niche, youth are often portrayed as a problem, a danger to adult society or, even worse, irrelevant to the future" ( $p$. xiv). Other than the limited data generated by standardized surveys of "youth attitudes" on a broad range of issues (e.g., Bibby, 2001; Griffith \& Labercane, 1995) students have rarely been engaged in meaningful ways in educational research on anti-racism activism, and their understandings of the nuances of 
work in this area remain largely unexamined. This project has engaged student participants as leaders in the struggle to make schools more equitable.

\section{Theoretical Framework}

Dei's (1996) notion of "integrative anti-racism" is used as an entry point for focusing our attention on a small number of specific school-based efforts to address discrimination and inequities in collaborative ways. Integrative antiracism addresses the "problem of discussing the social constructs of race, class, gender, ability and sexuality as exclusive and independent categories" (Dei, 1996, p. 55). Although the race, class, gender trilogy has been a focal point for social justice scholars and activists for years, integrative anti-racism builds on existing knowledge to develop a framework specifically for education. It is an activist praxis that disrupts singular, hierarchical meta-narratives as it problematizes the myriad interlocking forms of oppression. It acknowledges that different forms of oppression have different social effects, yet there is a "theoretical inadequacy of singular, exclusive constructs when it comes to explaining the diversity of human experiences of oppression" (p. 56).

Our study attended to "the social meaning of race and its intersections with other forms of social difference and oppression" (Dei, 1996, p. 19) such as the gender, ethnicity, sexuality, country of origin and migration patterns. Exploring issues of race as they intersect any of these social identities makes integrative anti-racism a valuable approach for the study of youth activism. We defined anti-racism activism for this research as direct action by a voluntary coalition of students and teachers to raise awareness or bring about social change toward eliminating racism and other forms of discrimination. Anti-racism activism can include organizing educational programs, displays, group activities, awareness events, media campaigns, and other political engagement on issues of difference and ethnicity from a critical lens that acknowledges links with other forms of oppression. Direct involvement in any social justice initiative was explored as it intersected issues of race, gender, class, ability, and sexuality. The list of guiding questions for the interviews (see Appendix) explored what links, if any, existed in youth anti-racism involvement with other forms of oppression, as well as the level of analysis and connection made by students in their mobilization efforts.

\section{Methodology}

Four longtime social justice activist colleagues collaboratively generated initial research questions for a pilot study. The researchers formulated guiding but flexible research questions generated from experiences and research in this field. Seeking a respectful and collaborative engagement with the everyday activism of the student participants, the researchers adopted features of a critical ethnographic approach (Carspecken, 1996) adapted based on prior research. While paying deliberate attention to our own values and assumptions, the 
researchers sought to understand participants' perspectives in their own terms, through a collaborative interview process of discovery and analysis (Fine \& Weis, 1996).

Lund positioned the pilot study as a vehicle both for facilitating and evaluating anti-racism activism and as an instrument of community-building among committed teachers and students. Rather than deny or downplay our past experiences in the field, the researchers in this study utilized their roles as "insiders" to obtain more relevant and sound data. The two main guiding research questions were:

1. How do secondary high school students conceptualize and articulate their anti-racism activism?

2. How might these understandings, based on the lived experiences of school-based anti-racism activists, inform research, policies, and programming for immigrant, refugee, and other marginalized students?

During the initial phases of the project, the researchers took a survey of existing programs and resources, including recent research conducted on the use of specific anti-racism and diversity resources across this particular region. Interviews were held with 13 high school activists (students and teachers) who had recently undertaken projects to foster the acceptance of immigrant students within their schools. Field visits entailed meeting with activists in major cities in each of the western Canadian provinces of Alberta, Saskatchewan, and Manitoba. Activists were selected using a variation of convenience sampling methods, primarily through word of mouth and contacts with community workers, teachers and other professionals, and others in the social justice field. The researchers conducted field observations and in-depth collaborative interviews with seven students and six adult participants following protocols of critical ethnography (Carspecken, 1996). Efforts were made to sample a diverse mix of students from schools representing a range of cultural and socioeconomic demographics and a balance of gender, age, and other characteristics. This paper focuses on data from interviews with the seven student participants.

Interviews of approximately one hour in length were held in familiar and private places where interviewees felt comfortable sharing their thoughts away from other students or teachers. Students had ample opportunities to share their thoughts and reflections from their experiences within a non-threatening environment where the guiding questions could be answered organically through informal discussion. Insights from these few students are not meant to be representative of a larger population of activists, but rather to provide insights into the specific motivations of a few actual student activists whose views have much to offer scholars and policy-makers in this field. The interviewers' past experiences with collaborative youth anti-racism work created an opportunity to 
share experiences reciprocally and to discuss at length some of the aspects of this work that are usually shared only within insular activist communities.

\section{Participant Selection}

The interviewees ranged in age from 15-20 years old and were either attending high school or volunteering with peers in school-based initiatives. The interviewees came from diverse range of socioeconomic, cultural and ethnic backgrounds, representative of the demographics of Alberta, Saskatchewan, and Manitoba (Statistics Canada, 2006). The interviewees came from two distinct camps; the first group can be broadly characterized as privileged middle-toupper-class youth, a majority of whom are White and who were introduced to this work through supportive activist parents. For example, this was the case with Amanda ${ }^{3}$ and Stephanie, who commented that their families' activism background and anti-racism dinner table conversation had been instrumental to their current social consciousness. Both Amanda and Jason, whose father had been leading students in anti-racism initiatives for the past 30 years in his role as a teacher, reflected that their engagement in this work felt like a natural progression in their learning and development, and neither could identify an "ahha" moment that led them to this work. Likewise, Maya said, "My personal belief is that people are shaped by their circumstance. So my family is heavily involved in all aspects of our community... everyone in my family is really upfront about things like that, so they influenced me in taking initiative." This group of four students felt empowered and supported in all their pursuits, and in all cases they expressed that they felt a duty to the work because of their heightened social consciousness.

The other three student interviewees came from much different backgrounds; they were either first generation Canadians or had immigrated to Canada and expressed that either they or their parents had personally experienced racism. These students often wove stories of their families and immigration into the mix of reasons that they were committed to anti-racism work. Michael, who came to Canada as a refugee from Southern Africa, said that exposure to poverty in his home country has made him realize that in Canada people suffer differently and that being Black is a major impediment in Canadian society. He broke down while recalling a conversation: "We also talked about what it's like for new immigrants when they come to the country. How others make fun of them, how they pronounce the words... [crying]." Jasmine, like Michael, immigrated to Canada with her family and commented that, because she had lived in poverty in the Philippines, her commitment to anti-racism work was simply "a way to give back." 


\section{Interview Findings}

The participants' level of analysis of the concepts of racism and integration varied greatly, ranging from a grounded understanding of the multiple and complex dimensions of racism and its social and political implications for immigrant and refugee students, to an engagement in activism because of the participants' very personal, raw experiences. Although all students we interviewed understood that there was a need to challenge the status quo in terms of how racism manifests itself in Canadian society, their approaches toward school activities were wide-ranging, and roughly followed Banks' (2002) analysis of forms of multicultural education-from cultural contribution, to additive, to transformative, to social action approaches (pp. 29-32). Specifically, the students we interviewed organized school activities that ranged from traditional multicultural sharing, to creating awareness in safe and inclusive school environments, to more confrontational grassroots action.

Specific projects included formalized programs by teachers for students, such as creating a video-commercial for combating racism as part of a nationwide competition. In this case, the students had little anti-racism awareness; through a very collaborative process, they intuitively created a powerful video depicting the emotional and psychological effects of racism. Another project included an overnight refugee simulation exercise, in which students experientially learned about some aspects of being a refugee, specifically segregation based on ethnicity, age, gender and other aspects of social identity. Interestingly in this case, racism became a catch-all phrase for any form of oppression that students were experiencing. Another project included a wellestablished, multi-school initiative for creating awareness of multiple forms of oppression, namely racism, in which youth leaders are chosen to participate in and, with additional training, eventually lead sessions for their peers.

There were also a number of student-initiated groups and events. The broad range included a school-wide multicultural show in efforts to build understanding of other cultures and minimize hallway racist comments to a more engaged social justice group. Here, students identified various causes they wanted to be involved in and, through their process of involvement, created awareness and engagement among other students in the school. In a different scenario, one of the participants shared that during his junior high school years, he and his friends became increasingly aware of racism in his city and took to the streets to confront racist behaviors; their involvement became more sophisticated as they went on to build websites with pertinent anti-racism information, engaged fellow students, and eventually began organizing national-level anti-racism conferences and events. The interviews yielded three overarching themes that were pertinent to all interviewees regardless of their individual level of engagement and analysis. These included how and why they got involved, the social impact of their involvement, and their success and struggles; these themes had emerged in recent social justice research with student activists (Lund, 2006) 
and were echoed by specific salient questions on youth agency raised by Giroux (2003, pp. 142-146).

\section{Reasons for Involvement}

There are arguably as many personal reasons for getting involved in school social justice projects as there are student activists. With this small but diverse group of student leaders, their earliest interests in equity issues ranged from painful personal experiences with racism and discrimination in Canada, to acting on global awareness of injustice, to growing up within families that encouraged and promoted anti-racism activism, to sheer accident. For Michael, immigrating to Canada after his father died, his initial drive to choose to work in a coalition to promote social justice was borne from his own lived experience:

The drive came from my personal education. I was raised in a really poor family and we didn't have much. We had to have faith and believe in God that we'd have food. You know in South Africa people sell things on the streets; that's how we survived... But you weren't guaranteed an income. That's where my drive came from. I told my mom that there is a better life we can live.

Likewise, Jasmine, 19 years old, explained that her own experiences as an immigrant sowed the earliest seeds of her activism. Reflecting on her life in her home country in the Philippines, she said, "We actually lived in poverty... so I know how hard it was. So [through my activist work I am] just trying to give back to my mom." Jasmine also added her more self-directed motivations for engaging in activism in schools, including her own future academic and career advancement: "I think for me, it was just for myself... Maybe for me, getting involved will give me a chance to get more of the school and staff-also, to see where I'm going with my career. That's why I ran for [students' council] president, to see how far I could go with my skill." For both of these students, their experiences living in underprivileged, marginalized communities very much inspired their activist efforts in school.

Maya, a Canadian-born 17-year-old of Indian descent, offered a similar personal account of the origins of her wish to foster acceptance and promote social justice ideals: "I think the turning point for me was when I went back and visited my parents' home towns in India and you just see the people on the street begging for money. Ever since then, I've had the idea that if I can help, I will." Maya's socially conscious parents, living in a larger city on the Canadian prairies, also encouraged her to learn more about global concerns and to take action. Like Jasmine, Maya also explained that the intrinsic gratification she has received from helping is a key motivator for her:

The other half of it is that knowledge-knowing someone out there needs help and knowing that you can help them, the smallest way possible, 
probably [makes] the biggest difference to me, personally - the personal benefits that I gain from it.

She added that failing to act while having knowledge of injustice would cause her to feel guilty: "You know if I never did all the things that I do, I would feel this huge cloud of guilt. Knowing that you didn't help when you could have."

For the White mainstream students-and for those students of color who came from families they described as being more affluent and upper- to-middle class - their expressed motivations for activism emerged more out of a middleclass value of wanting to help those less privileged than by any personally experienced injustices. In many cases, family values and experiences also fostered their activism. Born and raised in a small city in Alberta in a White middle-class home, Stephanie had traveled extensively but never to developing nations. The 20-year-old talked about what initially got her interested in social justice activism:

My mom has always had a real interest in this type of stuff and she made me read the newspapers... We [siblings and I] always knew what was going on in the world. I wanted to do something but didn't know how to get involved; I knew what was going on in the world, but it was like, what do I do? I didn't know how to get into all those things.

Amanda, a White Canadian-born student from a city in Saskatchewan, now 20 years old and studying at university, talked of her family's strong influence on her wish to become an activist:

I think it is mostly because of my family; my family has been activists in anti-racism so I had that support and had seen that from the time I was little. Before I became an activist myself, I'd seen and heard it and when you say about family making comments, my Dad taught in [a Canadian prairie city] for his whole career-he's a principal-and he taught mostly First Nations students so I knew them, beyond the stereotypes, from the time I was little. So I think it makes a difference when you know someone as a person and not just as a statistic.

Both of these students were made aware of suffering and injustice in the world by their families, encouraged directly by their parents to be a part of the solution, and cited this as a key motivator in their wish to become activists in school projects.

Jason, a 19-year-old from a large Alberta city, reported that he grew up in a family for whom social justice activism was a way of life. He explained, "I don't remember anything besides being involved. I don't know where the initial idea came from." For at least one other student, the activism was admittedly quite accidental and stemmed from the filming of an anti-racist themed video 
commercial for a class project. Soni, 15 years old, whose affluent and welleducated parents immigrated to a large Canadian prairie city from India, said that her reasons for getting involved were almost accidental: "I think we filmed it and wanted to do well and get a good grade and that was the main initiative. But then when we won, we thought of the different possibilities. Different schools had started calling us and asked us to show it to them, so after that it started building." However, she also said she was not interested in doing further activism on this topic after graduating high school. For differing reasons, such as lived experiences, social awareness, and accessibility to initiatives, these students each showed a varying level of commitment to social justice activism, and all have taken deliberate efforts to foster inclusion and acceptance of diversity among their peers. As earlier mentioned, their experiences with school activism are varied, as are their analyses and ability to articulate that work, but many of them share similar stories about the many challenges to undertaking social justice activism in schools.

\section{Social Impact of Involvement}

Specific challenges to the young activists' work in schools included a variety of social struggles with peers while undertaking projects that address racism and other discrimination. Throughout their interviews the students addressed the widespread apathy they noted among many of their peers toward issues of diversity. Michael said he struggled with "the students who don't really see the benefits of what we're doing. They think that it's just a waste of time and they just want to get out of school and relax and it's hard for us." Amanda remarked, "I would say the biggest challenge with dealing with anti-racism is dealing with the people who are quiet about it, so you don't get inside their head and you don't really know what they're thinking." Stephanie also encountered apathy when first trying to recruit for their school's social justice program, but only with certain segments of the student population: "Either they were into it and they were like, 'let's do something' or they didn't care. But it was all good. We actually had a few [student athletes] who were involved in it at the end. All cliques were involved in it." Talking about the same school, Samira recounted, "I guess the biggest challenge is getting [student] participation. I've actually never had trouble with people signing up; it's more getting the student body to participate."

Additionally, student participants brought up specific challenges of dealing with peers who do not seem to understand their deep commitment to social justice concerns. As Amanda recounted, taking a stand with peers on matters pertaining to racism or discrimination can come with negative consequences:

I took a lot of harsh words from friends because they would make a joke and I'd be the one saying, "You know this isn't funny. Do you realize what you just said?" And so I think it was too much work for them; they didn't like that they couldn't just go out and have a good time because they knew 
that someone was listening to them. One friend in particular in high school would say, "Everyone stop talking, 'Love Everyone' is here" when I would walk into the room.

Being a young person comes with enough challenges as students make their way through secondary school, but to take on an activist concern for social justice issues added another layer to their already complex social life.

Jasmine recounted her disappointment with some students who attended an awareness-raising event about refugee issues. She had taken an active leadership role in organizing a role-play experience and found that a few students had chosen to attend the workshop for the wrong reasons:

My biggest challenge was that I heard some of the students saying, "Oh we just wanted to come to this so we could skip school," but I would try to get them into their roles. I was trying to get them to realize that this experience is very important. Some would say that they didn't know anything about refugees and just wanted to miss school, but at the end when I gave them letters from refugees, it was really effective.

Jasmine's perseverance and determination to educate her peers can serve as a helpful reminder of the need to persist; she is, in many ways, an admirable role model for teacher and community activists who may be tempted to give up with students they perceive as unmotivated.

Amanda said that she found that for social justice projects to be successfully implemented and sustained there must be a certain level of peer acceptance. This often entailed efforts to "win over" the perceived student leaders. She explained how the "cool" factor can be crucial to a group's survival:

The schools where there has been a stigma to [activism] haven't been successful... and this is why the first core group of students is generally chosen. We try to get teachers to choose a couple of the "cool" kids and a couple of the "nerdy" kids that maybe are bullied, and we try to keep it so that it is fairly multicultural, so that it's not just a bunch of Caucasian people... In my school it was considered very successful, but also kind of a cool group to be a part of.

Stephanie also recounted how the first generation of her school's social justice club benefited from being seen by students as something "cool": "The original kids who started it were the cool kids, so they were in that crowd anyways. It was like 'Oh, you're in [the social justice club]? That's awesome.' It was like the basketball team." These students' candid observations shine light on the complex hierarchies that exist within schools and serve as reminders that any new school initiatives, even social justice clubs that seek to model equity and 
acceptance, must negotiate their own space within a school's complex social network.

For some students, their social justice efforts in school were met with overwhelmingly positive support. Erin's successful "March 21" anti-racism campaign attracted the attention of the outside media and also her peers: "When they saw the effects that it had and that the people from 'Racism-Stop it' thought that it conveyed a good message, they felt good about it. And they were excited that it was going to be on TV!" With a similar success, Soni said that after the production of her anti-racist video project was undertaken with the cooperation of the larger school population, "They were all our friends and they were really great and supportive about participating. I think the whole school really showed a great sense of support, before and after." The recognition was also a source of pride for her parents: "They were so proud! They framed the pictures from the [newspaper]. My Dad tells his patients!"

Likewise, Maya was buoyed by the many benefits to the school community, some unplanned, that emerged from their social justice project:

The main idea was to raise money for the grad committee, but in the end something more than that. And the kids in school, the ESL department specifically, really benefited from it because they got to showcase their talents and watch other people who had the same talents, but aren't necessarily in the same class. I think it made them feel more accepted, knowing that their culture isn't one that is going to have any racism against it. I think it really built up tolerance and a lot of people supported it and a lot of the staff supported it as well.

Maya said that she found the acceptance she received at school for her leadership in a refugee simulation project spilled over in a positive way to her home life: "I think once you get recognition from your peers and from people at school and they let your parents know, they start to realize that it's worth it!" Some of the challenges these activists said they faced came from the adults in their community whose stereotyped or limited views on young people frustrated their activist efforts.

\section{Successes and Struggles}

There was a shared concern among our participants that youth are not being taken seriously by the adult community. Stephanie observed, "People don't take you seriously. You're a student, you don't care-they just don't take you seriously. It's actually really frustrating... I tried to do something with [an international aid agency] and they were like 'Sorry, you're not qualified' and I would think, I want to volunteer, what does it matter?" Her frustration with being marginalized or devalued due to her age was also evident in Michael's account of his experiences. He recounted trying to address a diversity issue at a meeting 
with teachers in his school: "I raised my hand and said that the majority of the population in the school is the students, so if you're going to talk about change, why don't you include us in the process? They looked at me and thought that I had a point." It takes moments of courage such as this for students to find and use their voices, in order to be taken seriously by adults and be respected as valued collaborators in social justice activism.

When asked directly, many young people indicated that they wished to be involved in collaborative approaches to develop what Pruegger and Kiely (2002) call "youth created and directed solutions" to racism (p. v). Some young people actively seek greater involvement with an adult community that may be skeptical or unwilling to engage with young people. Stephanie noted that young people find themselves with a growing awareness of local and global injustices but may become frustrated by what they perceive as adult indifference or inaction:

Kids were noticing that something is going on. Things are happening in the world and they don't know what to do about it. They are growing up in a place where they were taught to something about it, even if it is racism. So I guess the students were ready for it, to have something in place, even if everyone else wasn't... I tried to talk to adults but they were like, who cares. So it was really nice to have an outlet.

Stephanie said that she felt disillusioned by the ultra-right-wing conservative federal politician who represents her area and expressed regret that her social justice group could not expect support from the political leadership in her region of Alberta:

I think it would be really nice to have...not so much government support, but people like [our Member of Parliament] to come out, but he's Conservative, so it wouldn't work! But anyway to have him come out and say, "Oh this is good," and to pay attention.

Her expressed desire for greater support from the adult communityparticularly her teachers and the elected political leadership-serves as a clear call for more committed adults to come forward and take an active role in working collaboratively with young people in their efforts toward social justice.

For Michael, the adults within the school played a vital supporting role for student activism, and he hoped they would become motivated by the students' successes: "If we show other people the benefits of [our anti-racist program] then the teachers and principals will encourage us. I think teachers play a major role." Samira noted how helpful her adult mentors had been in organizing social justice-themed events: "It's always sort of a challenge to plan these things-there is a lot of extra work and it's frustrating - but our teacher did a lot of that." Engaging students in collective efforts toward social justice in schools will entail more than having a token youth representative on a diversity committee or 
conducting a limited student attitude survey. Building authentic engagement and ownership involves teachers working alongside students in creating opportunities for trusting relationships to develop within respectful and reciprocal organizational structures (Lund, 2003) and confronting the forms of racism that are often imbedded in the views and experiences of White mainstream teachers (Marx, 2004; Solomon \& Daniel, 2007).

\section{Conclusion}

The interview data revealed student activists who are excited to talk about the work that they are doing and express the importance of taking their activism work outside of their communities. Although the students themselves did not appear to address specific intersections of race and culture with other forms of oppression in their interviews with us, we remain conscious of how our own views of an integrative anti-racism must attend to all forms of oppression. Perhaps the students felt limited by our lines of questioning or by the nature of the specific projects on which they had worked. Even when sharing the significant barriers and obstacles to the work, the students remained optimistic overall. Amanda expressed,

I think that the challenges are also the good things. I think when you confront those challenges and are able to overcome them is the best thing. If you weren't able to overcome any of the challenges, you wouldn't continue with this type of work.

Amanda noted some observable improvements in her high school's climate regarding her peers accepting formerly marginalized students: "One thing we hear from kids is that people just get along better and that everyone's friends with that First Nations girl now. They're not scared to talk to her." Likewise, for Maya, it was sometimes the small changes she noticed that made her work worthwhile. She recalled the observable positive outcomes of a recent awareness-raising activity: "I think it was seeing the reaction on their faces... We also got a lot of the shyer kids voicing their opinions."

Each of the emerging themes from students' insights, as expressed to us in this study, reflected our guiding ideas about how school activists initially get involved, experience and counter resistance from peers and adults, and foster acceptance and commitment among their fellow students. Together, these accounts and analyses offer a revealing glimpse into the lived experiences of racism and the efforts of those who try to challenge it from within schools in communities. Following up on these initial findings with additional studies of young people engaged in activism on a broader range of oppressions will offer further implications for curriculum development, professional development for educators, teacher education, educational policy, and government anti-racism policies. 
These student activists told us they were excited to talk about the antiracism work they do and expressed the importance of working collaboratively with adults and taking this activism outside of their communities. By acknowledging and studying their efforts we are answering Dei and James' (2002) call to educators to "enable students to use their individual collective agencies to work for change that furthers equality, thereby enriching a strengthening our social fabric" (p. 83). The strengths, limitations, opportunities, and challenges expressed by our young interviewees revealed potential areas we hope to explore more deeply as we analyze the intersections of attitudes and practices with their adult counterparts. We look forward to sharing further findings and analyses from the teacher participants as the research and our ongoing activism continue to unfold.

\section{Notes}

1. This research was supported by the Social Sciences and Humanities Research Council, through a research grant from the Metropolis Project, Prairie Centre of Excellence for Research on Immigration and Integration. A modified version of this paper was presented in March 2006, at "Immigration and Canada's Place in a Changing World," the $8^{\text {th }}$ National Metropolis Conference in Vancouver, British Columbia, Canada.

2. The Diversity Toolkit is available for viewing at http://www.ucalgary.ca/ dtoolkit.

3. All names used are pseudonyms.

\section{References}

Alberta Human Rights Commission. (1993). A survey of attitudes toward human rights and toward self in Alberta schools: Technical report. Edmonton, Alberta, Canada: Government of Alberta.

Alberta Human Rights and Citizenship Commission. (2000). Tools for transformation: Human rights education and diversity initiatives in Alberta. Edmonton, Alberta, Canada: Government of Alberta.

Apple, M. (1999). Power, meaning, and identity: Essays in critical educational studies. New York: Peter Lang.

Banks, J. A. (1998). The lives and values of researchers: Implications for educating citizens in a multicultural society. Educational Researcher, 27(7), 4-17.

Banks, J. A. (2002). An introduction to multicultural education ( ${ }^{\text {rd }}$ ed.). Boston: Allyn \& Bacon.

Bibby, R. W. (2001). Canada's teens: Today, yesterday, and tomorrow. Toronto, Ontario, Canada: Stoddart. 
Boyko, J. (1995). Last steps to freedom: The evolution of Canadian racism. Winnipeg. Manitoba, Canada: Watson \& Dwyer.

Carspecken, P. F. (1996). Critical ethnography in educational research: A theoretical and practical guide. New York: Routledge.

Corson, D. (2000). A pan-Canadian research program for more inclusive schools in Canada: The diversity and equity research background. In Y. Lenoir, W. Hunter, D. Hodgkinson, P. de Broucker, \& A. Dolbec (Eds.), A panCanadian education research agenda (pp. 167-191). Ottawa, Ontario, Canada: Canadian Society for Studies in Education.

Creese, G., \& Kambere, E. N. (2003). What colour is your English? Canadian Review of Sociology and Anthropology, 40(5), 565-573.

Dei, G. S. (1996). Anti-racism education: Theory and practice. Halifax, Nova Scotia, Canada: Fernwood.

Dei, G. S. (1996b). Theory and practice: Anti-racism education. Halifax, Nova Scotia, Canada: Fernwood.

Dei, G. S., \& Calliste, A. (Eds.). (2000). Power, knowledge and anti-racism education: A critical reader. Toronto, Ontario, Canada: Fernwood.

Dei, G. S., \& James, I. M. (2002). Beyond the rhetoric: Moving from exclusion, reaching for inclusion in Canadian schools. Alberta Journal of Educational Research, 48(1), 61-87.

Dei, G. S., James, I. M., James-Wilson, S., Karumanchery, L. L., \& Zine, J. (2000). Removing the margins: The challenges and possibilities of inclusive schooling. Toronto, Ontario, Canada: Canadian Scholars' Press.

Fine, M., \& Weis, L. (1996). Writing the "wrongs" of fieldwork: Confronting our own research/writing dilemmas in urban ethnographies. Qualitative Inquiry, 2(3), 251-274.

Ghosh, R. (1996). Redefining multicultural education. Toronto, Ontario, Canada: Harcourt Brace.

Ghosh, R., \& Abdi, A. A. (2004). Education and the politics of difference: Canadian perspectives. Toronto, Ontario, Canada: Canadian Scholars' Press.

Giroux, H. A. (1996). Fugitive cultures: Race, violence, and youth. New York: Routledge.

Giroux, H. A. (2003). The abandoned generation: Democracy beyond the culture of fear. New York: Palgrave MacMillan.

Griffith, B., \& Labercane, G. (1995). High school students' attitudes towards racism in Canada: A report on a 1993 cross-cultural study. In K. A. McLeod (Ed.), Multicultural education: The state of the art, Report \#2 (pp. 144-151). Winnipeg, Manitoba, Canada: Canadian Association of Second Language Teachers. 
Hall, S. (1992). New ethnicities. In J. Donald \& A. Rattansi (Eds.), "Race," culture, and difference (pp. 252-259). London, UK: Sage.

James, C. E. (2005). Perspectives on multiculturalism in Canada. In C. E. James (Ed.), Possibilities and limitations: Multicultural policies and programs in Canada (pp. 12-20). Winnipeg, Manitoba, Canada: Fernwood.

Li, P. (2003). Deconstructing Canada's discourse of immigrant integration. Journal of International Migration and Integration, 4(3), 315-333.

McCarthy, C., \& Dimitriadis, G. (2005). Governmentality and the sociology of education: Media, educational policy, and the politics of resentment. In C. McCarthy, W. Crichlow, G. Dimitriadis, \& N. Dolby (Eds.), Race, identity, and representation in education ( $2^{\text {nd }}$ ed., pp. 321-335). New York: Routledge.

Moodley, K. A. (1995). Multicultural education in Canada: Historical development and current status. In J. A. Banks \& C. A. McGee Banks (Eds.), Handbook of research on multicultural education (pp. 801-820). New York: Macmillan.

Nieto, S. (2004). Affirming diversity: The sociopolitical context of multicultural education ( $4^{\text {th }}$ ed.). New York: Allyn \& Bacon.

Pruegger, V., \& Kiely, J. (2002). Perception of racism and hate activities among youth in Calgary: Effects on the lived experience. Calgary, Alberta, Canada: Community Strategies.

Sleeter, C. E. (1996). Multicultural education as social activism. Albany, NY: SUNY Press.

Sleeter, C. E., \& Bernal, D. D. (2004). Critical pedagogy, critical race theory, and antiracist education: Implications for multicultural education. In J. A. Banks \& C. A. McGee Banks (Eds.), Handbook of research on multicultural education ( $2^{\text {nd }}$ ed., pp. 240-258). San Francisco, CA: Jossey-Bass.

Solomon, R. P., \& Daniel, B-J. (2007). Discourses on race and "white privilege" in the next generation of teachers. In P. R. Carr \& D. E. Lund (Eds.), The great white north? Exploring whiteness, privilege and identity in education (pp. 161-172). Rotterdam, Netherlands: Sense.

Solomon, R. P., \& Levine-Rasky, C. (2003). Teaching for equity and diversity: Research to practice. Toronto, Ontario, Canada: Canadian Scholars' Press.

Solomon, R. P., \& Rezai-Rashti, G. (2001). Teacher candidates' racial identity development and its impact on learning to teach. Directions, 1(1), 52-59.

Statistics Canada. (2002). "Ethnic diversity survey. Ottawa, Ontario, Canada: Government of Canada." Retrieved January 6, 2008, from http://www.statcan.ca/english/sdds/4508.htm

Statistics Canada. (2006). "Census trends. Ottawa, Ontario, Canada: Government of Canada." Retrieved January 6, 2008, from 
http://www12.statcan.ca/english/census06/data/trends/Table 1.cfm?T=PR \&PRCODE $=01 \& G E O C O D E=01 \& G E O L V L=P R$

Yon, D. A. (2000). Elusive culture: Schooling, race and identity in global times. Albany, NY: SUNY Press.

\section{Appendix}

\section{Interview Questions}

General Information:

1. What grade are you in?

2. In what courses or school programs are you presently enrolled?

3. How long have you been at this school? In this community?

4. Have you taken any courses related to the areas of diversity or social justice?

5. Do you have any special training in social justice activism?

6. How did you become interested in working with other students/teachers on these issues?

7. Are you involved in any other social justice activism outside of this group?

8. How much time do you invest in your activism work?

General Information Regarding Social Justice Project:

9. What is the organizational structure of the social action project (i.e., size, demographics, meeting schedule, format, roles, etc.)?

10. How would you describe your role within the group/project?

11. How many students and teachers are presently involved?

12. How long has the organization been in existence at this school?

13. On what specific or general areas or topics does the project focus?

14. What are the objectives or goals of the group?

15. To what extent has the group been successful in attaining these goals?

16. To what do you attribute the group's greatest achievements?

17. What challenges or barriers has the group faced?

Specific Information on the Project's Efficacy/Challenges: 
18. How does the group actively recruit members?

19. Is the group considered part of the school's regular extra-curricular program?

20. Does the group seem to have the administration's support? If so, explain.

21. Does the group seek community involvement? If so, explain.

22. What are the present specific activities or planned activities of the group?

23. What are some past activities of the group?

24. How would you measure or evaluate the success of specific activities?

25. In what ways does the group attempt to bring about social change (i.e., on classroom, school, community, global issues)?

26. How could the group improve its success in dealing with social justice issues?

Specific Questions on Backlash

27. Has the group faced any challenges, now or in the past?

28. How has the group addressed these challenges?

29. How could the group better address these challenges?

30. How has the group received support?

31. What other types of support would be helpful? 